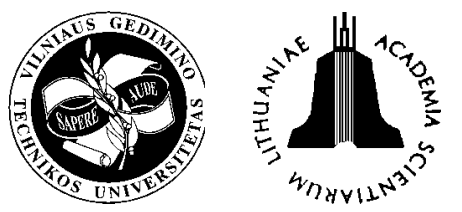

ISSN 1648-4142 TRANSPORT

http:/www.vtu.lt/english/editions

TRANSPORT-2004, Vol XIX, No 6, 252-261

\title{
IMPROVEMENT OF THE PARAMETERS OF MAINTENANCE OF MEDIUM SPEED DIESELS APPLYING THE MOTOR METHODS
}

\author{
Sergejus Lebedevas ${ }^{1}$, Andrius Vaicekauskas ${ }^{2}$ \\ Klaipeda University Maritime Institute, I. Kanto g. 7, LT-92123 Klaipéda, Lithuania \\ E-mail:12_Sergejus@mail.ru, 2 andrius@swelbalt.lt \\ Received 2004-04-12; accepted 2004-10-05
}

\begin{abstract}
The problem of the improvement of parameters of maintenance of medium speed diesel engines is described in the publication. The most rational way of solving this problem is the performing of calculational research by using modern programs of mathematical modelling. At the initial stage of the research the approbation of interapplication of computer programs with a different level of elaboration for the optimisation of the main indexes of medium speed diesel engines (fuel economy, reliability, emission of harmful components in exhaust gases) is performed. The investigated efficiency of separate motor methods was applied for diesel engines 6VDS 48/42 AL-2 which are widely spread in the fleet of Lithuania. For the performance of further investigations the indirect criterion which estimates the phase of kinetic combustion and emission of nitric oxides is offered.
\end{abstract}

Keywords: diesel, parameters of work process, mathematical modelling, optimisation, motor methods, harmful component's emission

\section{Introduction}

Large majority of the diesels fleets operating in Lithuania, including engines of ships, consists of diesel models made in 1980-1990 [1, 2]. The parameters of their fuel economy are significantly lower than of modern diesels and this determines a high level of operational costs and lower profitability of sea carriage of goods. The leaders of diesel engine manufacturers (MAN B\&W, Wartsila, Sulzer, Mitsubishi, MaK, Pielstick, Caterpillar) have achieved a high level of diesel engine technical - economical parameters $[3,4]$. The ecological parameters require not less attention and first of all the emission of nitric oxides which is regulated by VI Annex of convention MARPOL 73/ 78 stated by IMO on $5^{\text {th }}$ of October 98 [5].

All leaders of diesel engine manufacturers meet the requirements of emission of nitric oxides from 1990 without the ratification of the mentioned annex. The sanctions of penalty are applied in territorial waters of several Scandinavian countries and the USA for the vessels which power plants don't meet the requirements of VI Annex of convention MARPOL 73/ 78. For the named reasons the analysis of the improvement of operational parameters of ship diesels must be complex regarding fuel economy, toxicity of exhaust gases and parameters of diesel reliability. This mission can be carried out by universities, including the Maritime Institute of Klaipeda University associated with the training of specialists in this field and solving the tasks of maintenance of diesel engines.

The rational way of solving this task and reducing the input of time and finance is to pursue the calculating research applying modern PC programs of mathematical modelling. The criteria of reliability of the obtained results would be a local experiment on the ship under operational conditions. Such experiment would be the source of initial data for the harmonizing of a mathematical model.

The results of an initial stage of the researches are reviewed in this publication. The objectives of the research were:

- the evaluation of the effectiveness of complex application of programs of mathematical modelling using the limited amount of experimental data of operational and working parameters of medium speed diesel engines;

- the evaluation of the possibilities of improvement of fuel economy and of reducing of $\mathrm{NO}_{\mathrm{x}}$ emission applying the motor methods influencing the parameters of regulating and indicated work.

The object of the research was the diesel 6VDS 48/42-L2 made in 1989 by the company SKL Motor $\mathrm{GmbH}$ (Germany). The choice was determined by the fact that these diesels were used as the main en- 
gines on the ships of the company $\mathrm{AB}$ "Lisco Baltic Service" which was the leader of the carriage of sea goods in Lithuania.

The total installation power of engines of this type was $31,8 \mathrm{MW}$ or almost $35 \%$ of total power of all main engines of ships of the company in 2004.

\section{Formation of mathematical models of the object of research}

The often practise of calculation research of parameters of diesels is jointly application of several mathematical models which differ by the level of elaboration of the applying object by the structure and implemented mathematical methods of solving the algorithm [6]. The higher reliability of results and validity of made solutions is achieved in such way. The analogical approach in this work is conditioned by the limited possibilities to perform the experimental measurements of parameters of a diesel under operational conditions for the formation of initial data for a mathematical model. The deficit of initial data for the higher level of mathematical models is solved by partially applying the results of modelling with the lower level of mathematical models with a relatively small amount of initial data.

The application of modern multizone mathematical models is purposeful in the subsequent stages of the research regarding a big amount of experimental data of the indicated characteristics of a diesel for harmonizing of a mathematical model with the object of research. The application of the approbated calculating methods based on unizone models regarding the working process and ecological parameters is technically profitable for the tasks of operational character.

The following computer programs were used in this work:

- "Characteristics" - intended for the calculation of operating characteristics of a diesel and integral parameters of a working process;

- "IMPULS" - intended for the modelling of inner characteristics, effective and indicated parameters of a diesel;

- "RVJA" - intended for the synthesis of indicated program of a diesel and for the calculation of emission of nitric oxides with reference to the characteristics of indicated work;

- "TOXIC" - intended for the modelling of formation of dynamics of parameters of toxicity in exhaust gases and for the evaluation of their final meanings.

The principle of mathematical modelling of $\mathrm{NO}_{x}$, $\mathrm{C}_{\mathrm{n}} \mathrm{H}_{\mathrm{m}}, \mathrm{CO}$ and smokiness in this work is based on phenomenological basis and empirical coefficients that allow achieving a good congruence of experimental and calculating results from the point of view of the engineer.

The first model "Characteristics" is based on the method of little increases [7]. The expressions of continuing processes in the cylinder of a diesel engine and adjacent systems are given in the confirmation of the simple linear equations. The functional dependences of continuing processes in the cylinder of a diesel engine and adjacent systems are given in the confirmation of the simple linear equations. The direct coherence between the increase of output parameter of a diesel engine and the increase of an independent variable influencing it are determined in such confirmation:

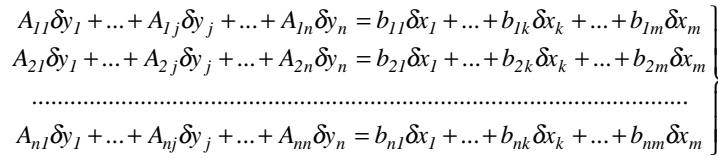

where:

$\delta x_{k}=\Delta x_{k} / x_{k 0}=\left(x_{k}-x_{k 0}\right) / x_{k 0}$-relative increase of an independent variable;

$\delta y_{i}=\Delta y_{j} / y_{j 0}=\left(y_{j}-y_{j 0}\right) / y_{j 0}-$ relative increase of searching meanings; $A_{i j}$ and $b_{j k}$ - coefficients of the influence of increase for searching meanings of independent variables; index " 0 " corresponds to primary meanings.

As an example, the change of a coefficient of efficiency of indicated work (when rotations and density of air before a cylinder of a diesel are constant $n$, $\rho_{k}=$ const) is expressed by the function of parameters of a diesel:

$$
\Delta \eta_{i}=K_{\alpha i_{i}} \alpha+K_{\varepsilon \eta i} \Delta \varepsilon+K_{\lambda i_{i}} \Delta \lambda,
$$

where:

$\Delta \alpha, \Delta \varepsilon, \Delta \lambda$ - relative increases of independent variables;

$K_{\alpha{ }_{i}}, K_{\varepsilon \eta i}, K_{\lambda \eta i}$-coefficients of $\alpha, \varepsilon$ and $\lambda$ influence on the coefficient of efficiency of indicated work $\eta_{i}$.

Coefficients of influence are determined generalizing results of more wide tests of diesel engines.

The system of equations is solved for each independent variable in such priority:

- the determination of the influence of digital meanings of primary data $x_{k 0}, y_{j 0}$ on coefficients $A_{i j}$ and $b_{j k}$;

- the calculation of the meanings of right side of the equations for given relative increases $\delta x_{k}$;

- the determination of radicals of the systems of equations;

- the calculation of new meanings of variables by formula 


$$
y_{j}=y_{j 0}\left(1+\delta_{y i}\right) .
$$

The analytical description of processes in the systems of a diesel engine is based on dependencies of classical theory of internal combustion engines specified by the results of experimental research. The physical processes in the diesel engine and its adjacent systems are considered quasi-stationary. Made assumptions ensures the precision of calculations.

The second model "IMPULS" is based on digital mathematical modelling of an indicated process of a turbo-piston engine [8]. Mathematical model is described by the system of differential equations including equations of expression of the law of stability of energy and mass and parameters of condition of gases in a cylinder of a diesel engine:

$$
\left\{\begin{array}{l}
\frac{d T}{d \varphi}=\frac{1}{c_{v} M}\left(Q . \frac{d g_{x}}{d \varphi}+\frac{d Q_{w}}{d \varphi}-c_{v} T \frac{d M}{d \varphi}-\frac{\pi V_{h}}{360} p b+i_{n} \frac{d M_{n}}{d \varphi}-i_{m} \frac{d M_{m}}{d \varphi}\right) \\
\frac{d M}{d \varphi}=g_{c} \frac{d x}{d \varphi}+\frac{d M_{n}}{d \varphi}-\frac{d M_{m}}{d \varphi} \\
p V=M R T
\end{array}\right.
$$

where: $Q_{\check{z}}\left(d g_{x} / d \varphi\right)$ - quantity of heat released at the combustion of a cyclical portion of fuel; $d Q_{w} / d \varphi-$ heat transferred to walls of a cylinder of a diesel engine; $i_{n}\left(d M_{n} / d \varphi\right), i_{m}\left(d M_{n} / d \varphi\right)$ - entered and released quantity of heat during the process of the exchange of gases in the cylinder; $d M_{n}, d M_{m}$ - elementary mass of fresh air and exhaust gases; $M$ - mass of work material in the cylinder of a diesel engine.

The first and second equations of the systems are differential and the first line under the given primary conditions. These equations are solved by applying computer mathematics methods under the schemes of final differences (Euler, Runge-Kuro etc.).

The solving of the first equation allows determining the array of values of temperature $\left(\mathrm{T}_{\mathrm{G}}\right)$ of a working body of an engine in the function of angle of rotation of crankshaft. The array of meanings of pressure $\left(\mathrm{P}_{\mathrm{G}}\right)$ of a working body is calculated using the third equation and on its basis with the use of the second equation the integrated parameters of the indicated work such as: average indicated pressure and specific indicated fuel consumption are determined.

Separate components of equations $\left(\mathrm{dg}_{\mathrm{x}} / \mathrm{d} \varphi, \mathrm{dx} / \mathrm{d} \varphi\right.$, $\mathrm{dQ}_{\mathrm{w}} / \mathrm{d} \varphi$ etc.) are determined solving the systems of equations. Function $\mathrm{dx} / \mathrm{d} \varphi$ is the basic and evaluates the law of heat released in a cylinder of an engine. Reliability of the results of mathematical modelling of parameters of processes of the diesel engine largely depends on the correctness of the mentioned function. The example of the results of mathematical modelling of characteristics of an indicated process is shown in Fig 1.

Substantial feature of the third model "RVJA" is its orientation to the solving of the tasks related with the research of processes of low and medium rotations of diesel engines [9]. This feature is used for the formation of a model of calculation of the extraction of heat (longer time of heat release), the determination of the effect of appliance of emulsion of waterfuel, the change of a number of cetane of fuel and other meanings.

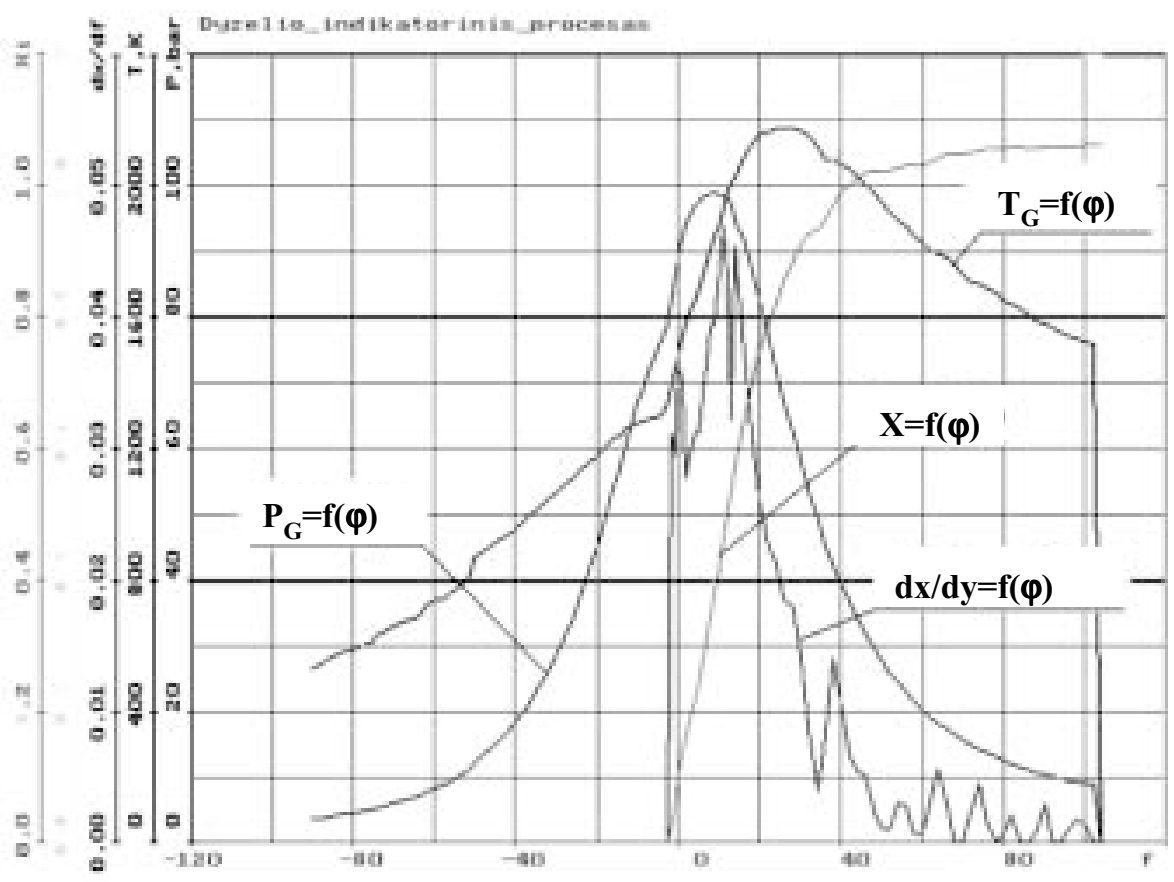

Fig 1. Results of mathematical modelling of characteristics of an indicated process (dependences of pressure and temperature of work body and heat producing) using program "IMPULS" 
The calculation of the emission of nitric oxides is based on the interdependence between dynamics $\left(\mathrm{de}{ }_{\mathrm{NOx}} / \mathrm{d} \varphi\right)$ of $\mathrm{NO}_{\mathrm{x}}$ formation and release of heat $(\mathrm{dx} /$ $\mathrm{d} \varphi$ ) that is determined practically and theoretically. The application of this model for the calculation of emission of nitric oxides for diesels MAN B\&W, Sulzer etc. allowed achieving good congruence of experimental and calculated results.

The results of experimental and calculating research of harmful indexes of diesel engines of medium and high speed that are obtained in Bauman Moscow State Technical University and Altai State Polzunov Technical University are generalized in the model "TOXIC" [10].

The results of the calculation of indexes of regime of nominal power of diesel 6VDS 48/42 AL-2 are presented in Table 1 . Obviously, the precision of the obtained results is very high in the case of their comparison among themselves and with the technical data of diesel engines given by their manufacturers. A relative error of the determination of the main parameters $\left(\mathrm{P}_{\mathrm{mi}}, \mathrm{T}_{\mathrm{g}}, \mathrm{b}_{\mathrm{e}}, \eta_{\mathrm{i}}\right)$ of a diesel engine doesn't exceed $\pm 1,5 \%$ and this ensures the conformability of the requirements of precision of determination of parameters on stand tests regarding the existing standards.

The congruence of the calculaed and experimental data for a wide range of load $\left(\mathrm{P}_{\mathrm{me}} \approx 1,6 \div 0,4 \mathrm{MPa}\right)$ and the rotation $\left(\mathrm{n}=500 \div 350 \mathrm{~min}^{-1}\right)$ of engines are principally important for the solution of practical tasks. Meanings of calculations of specific fuel consumption $b_{e}$ and its error $(\Delta b)$ from actual data of a manufacturer are presented in the field of universal characteristics $\mathrm{b}_{\mathrm{e}}=\mathrm{f}\left(\mathrm{P}_{\mathrm{me}}, \mathrm{n}\right)$ (Fig 2). The meaning of $\Delta \mathrm{b}$ doesn't exceed $\pm 2 \mathrm{~g} / \mathrm{kWh}$ or $1,0 \%$ in range of $75 \%$ of average effective pressure and $30 \%$ of rotation .

Positive results of approval ensure their further reasonable application in this work.
3. The analysis of the effectiveness of motor methods for the optimisation of a work process of a diesel engine

The motor methods are applied for the optimisation of characteristics of the indicated process of a diesel engine and intermediate adjustment for the improvement of operational parameters of profitability, ecology and reliability. Motor methods widely used in the practise of improvement and modernisation of diesel engines are:

- the optimisation of the main constructive and regulating parameters (a phase of fuel injection, a phase of apportionment of gases etc.);

- the optimisation of the parameters of air charge (a degree of increase of pressure, temperature of charged air) and their adjustment with the main constructive parameters;

the intensification of a process of fuel injection increasing the injecting pressure of fuel (increasing the speed of a plunger of high pressure pump, the application of systems of pump-injector or accumulatory systems with electronic devices of regulation, for example, Common rail);

- the injection of water directly into a cylinder with fuel (injection into a inlet manifold, injection directly into cylinder at the cycle of suction, the application of emulsion of water-fuel);

- the application of recirculation of exhaust gases: external - from the exhaust manifold to suction manifold by a by-pass valve, internal - ensuring the recirculation of exhaust gases by the retardation of the phase of closing an exhaust valve.

The limits of the effectiveness of the mentioned methods are wide and the methods are successfully used in practice. As an example the generalized data of company MaK of a manufacturer of medium speed diesel engine in Germany are presented (Table 2) [11].

Table 1. Collation of parameters of mathematical modelling and experimental tests of diesel 6VDS

\begin{tabular}{|c|c|c|c|c|c|}
\hline & \multirow{2}{*}{$\begin{array}{l}\text { Data of diesel } \\
\text { manufacturers }\end{array}$} & \multicolumn{3}{|c|}{ Results of modelling } & \multirow{2}{*}{$\begin{array}{c}\text { Relative error } \\
\Delta \delta, \%\end{array}$} \\
\hline & & "IMPULS" & "Characteristics" & "RVJA" & \\
\hline $\mathrm{n}, \min ^{-1}$ & 500 & 500 & 500 & 500 & 0 \\
\hline $\mathrm{P}_{\mathrm{e}}, \mathrm{kW}$ & 2650 & 2635 & 2650 & 2650 & $-0,6$ \\
\hline $\mathrm{P}_{\mathrm{me}}, \mathrm{MPa}$ & 1,59 & 1,58 & 1,59 & - & $-0,6$ \\
\hline $\mathrm{P}_{\mathrm{mi}}, \mathrm{MPa}$ & - & 1,81 & 1,79 & 1,84 & $\pm 1,35$ \\
\hline$\alpha_{\delta}$ & - & 2,08 & 1,94 & 2,07 & $\pm 3,2$ \\
\hline $\mathrm{T}_{\mathrm{T}}, \mathrm{K}$ & 818 & 802 & 828 & - & $\pm 1,5$ \\
\hline $\mathrm{T}_{\mathrm{g}}, \mathrm{K}$ & 668 & 695 & 727 & - & $\pm 4,0$ \\
\hline $\mathrm{P}_{\max }, \mathrm{MPa}$ & $11,8-1,0$ & 11,8 & 11,8 & 11,8 & 0 \\
\hline$\lambda$ & - & 1,45 & 1,56 & 1,60 & $\pm 4,6$ \\
\hline $\mathrm{b}_{\mathrm{e}}, \mathrm{g} /(\mathrm{kWh})$ & 206 & 206 & 203 & - & $\pm 0,7$ \\
\hline$\eta_{\mathrm{i}}$ & - & 0,477 & 0,467 & 0,472 & $\pm 1,0$ \\
\hline$\eta_{\mathrm{m}}$ & - & 0,875 & 0,888 & 0,875 & $\pm 0,7$ \\
\hline $\mathrm{e}_{\text {Nox }}, \mathrm{g} / \mathrm{Kg}$ fuel & - & - & - & 59,7 & - \\
\hline
\end{tabular}




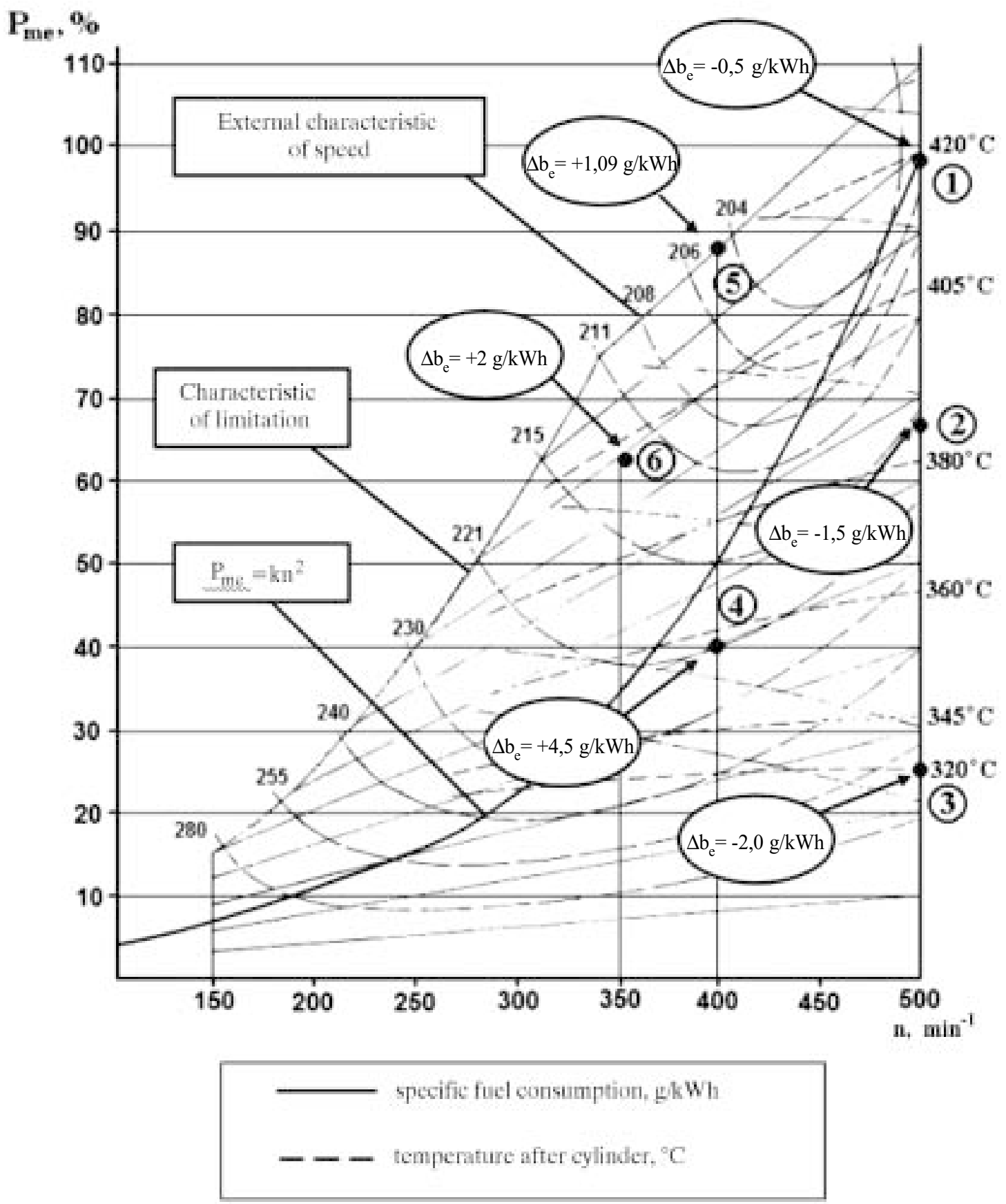

Fig 2. Collation of parameters of mathematical modelling and technical documentation of diesel 6 VDS 48/42 AL-2

Table 2. Results of mathematical modelling of parameters of diesel 6 VDS 48/42 AL-2

\begin{tabular}{|l|c|c|c|c|c|c|}
\hline & \multicolumn{7}{|c|}{ The point of working regime } \\
\cline { 2 - 7 } & $\mathbf{1}$ & $\mathbf{2}$ & $\mathbf{3}$ & $\mathbf{4}$ & $\mathbf{5}$ & $\mathbf{6}$ \\
\hline $\mathrm{P}_{\mathrm{me}}, \mathrm{MPa}$ & 1,59 & 1,08 & 0,43 & 0,363 & 1,40 & 1,00 \\
\hline $\mathrm{b}_{\mathrm{e}}, \mathrm{g} / \mathrm{kWh}$ & 205,5 & 215,5 & 263 & 225,5 & 205,8 & 215,0 \\
\hline$\Delta \mathrm{b}_{\mathrm{e}}, \mathrm{g} / \mathrm{kWh}$ & $-0,5$ & $-1,5$ & $-2,0$ & $+4,5$ & $+1,09$ & $+2,0$ \\
\hline
\end{tabular}


As a rule substantial improvement of fuel economy and ecology at the realization of one of the methods requires a lot of time and financial expenses.

The real efficiency of motor methods depends on the features of organisation of the indicated process of a researched diesel engine and the level of perfection of constructive and regulating parameters. For the mentioned reasons before choosing the method of perfection of a concrete diesel engine it is necessary to perform purposive research of the efficiency of motor methods.

The results of the research of parameters of a diesel 6VDS are examined in this publication. The evaluation of the efficiency of the reduction of specific fuel consumption and emission of nitric oxides for the optimisation of the constructive and regulating parameters and parameters of a turbocharger system is presented.

\subsection{Optimisation of a compression ratio and phases of fuel injection}

Increasing of compression ratio $\varepsilon$ positively influences the improvement of fuel consumption on the basis of cycles of thermodynamics, because a thermal coefficient of useful effect is expressed by the equation: $1-1 / \varepsilon^{\mathrm{n}-1},(\mathrm{n}-$ index of polytrope of compression). This process is attending by the increase of typical temperature of a cycle under equal other conditions. This increase influences the increase of $\mathrm{NO}_{\mathrm{x}}$ emission, the increase of maximal pressure of cycle $\mathrm{P}_{\max }$ the increase of mechanical stress of parts of a cylinder-liner group. The increase of the compression ratio of the diesel engine VDS 48/42 AL-2 from 12,5 in regular complete up to 14 , that can be really performed in practise, reduces the specific fuel consumption by $2 \%, \mathrm{P}_{\max }$ increases $\sim$ by $10 \%$. NOx emission is not increased, but decreases by $1,5 \sim 2 \%$.

It is explained that at a low enough initial level of the compression ratio, its increase up to $14(\sim$ $17 \%$ ), increases the temperature of an air charge during the stroke of compression. In its turn this influences the duration of the period of induction and reduces dynamics of a cycle, which determines the reduction of the phase of kinetics combustion $\mathrm{X}_{\mathrm{I}}$ from 0,55 to $0,47 \div 0,48$, during which, as it is known [12, 13], the largest amount of $\mathrm{NO}_{\mathrm{x}}$ is formed (see chapter 3). For preventing the increase of $\mathrm{P}_{\max }$ the increase of $\varepsilon$ should be performed according to the reduction of an angle of the start of fuel injection that is, the reduction of the angle of advance of fuel injection $\varphi_{\mathrm{ki}}$ on purpose of keeping the condition $\mathrm{P}_{\max } \approx$ const. $\mathrm{Re}-$ duction of $\varphi_{\mathrm{ki}}$ on $4^{\circ}$ of crankshaft rotation from the basic level with the increase of up to 14 , ensures $\mathrm{P}_{\max }$ $\approx$ const and be $\approx$ const, reduces $\mathrm{NO}_{\mathrm{x}}$ emission with exhaust gases $\sim 10 \%$, from $59,7 \mathrm{~g} /(\mathrm{kg}$ fuel) to $55 \mathrm{~g} /$ (kg fuel). In Fig 3 the collation of diagrams of the indicated process with regular regulation and with optimised meanings of $\varepsilon$ and $\varphi_{\mathrm{ki}}$ is presented.

Typical increase of pressure and the temperature of air and the reduction of $\varphi_{\mathrm{ki}}$ determine the reduction of the duration of period of induction $\varphi_{i}$ on $2^{\circ}$ of crankshaft rotation.

Conditional index of $\mathrm{X}_{\mathrm{I}}$ reduction from 0,55 to 0,43 is the reduction of a degree of increase of pressure $\lambda$. Under performed condition of $\mathrm{P}_{\max } \approx$ const and increased pressure of end of cycle $\mathrm{P}_{\mathrm{c}}$, parameter $\lambda$ reduces from 1,55 to $\sim 1,33$ (Table 3 ).

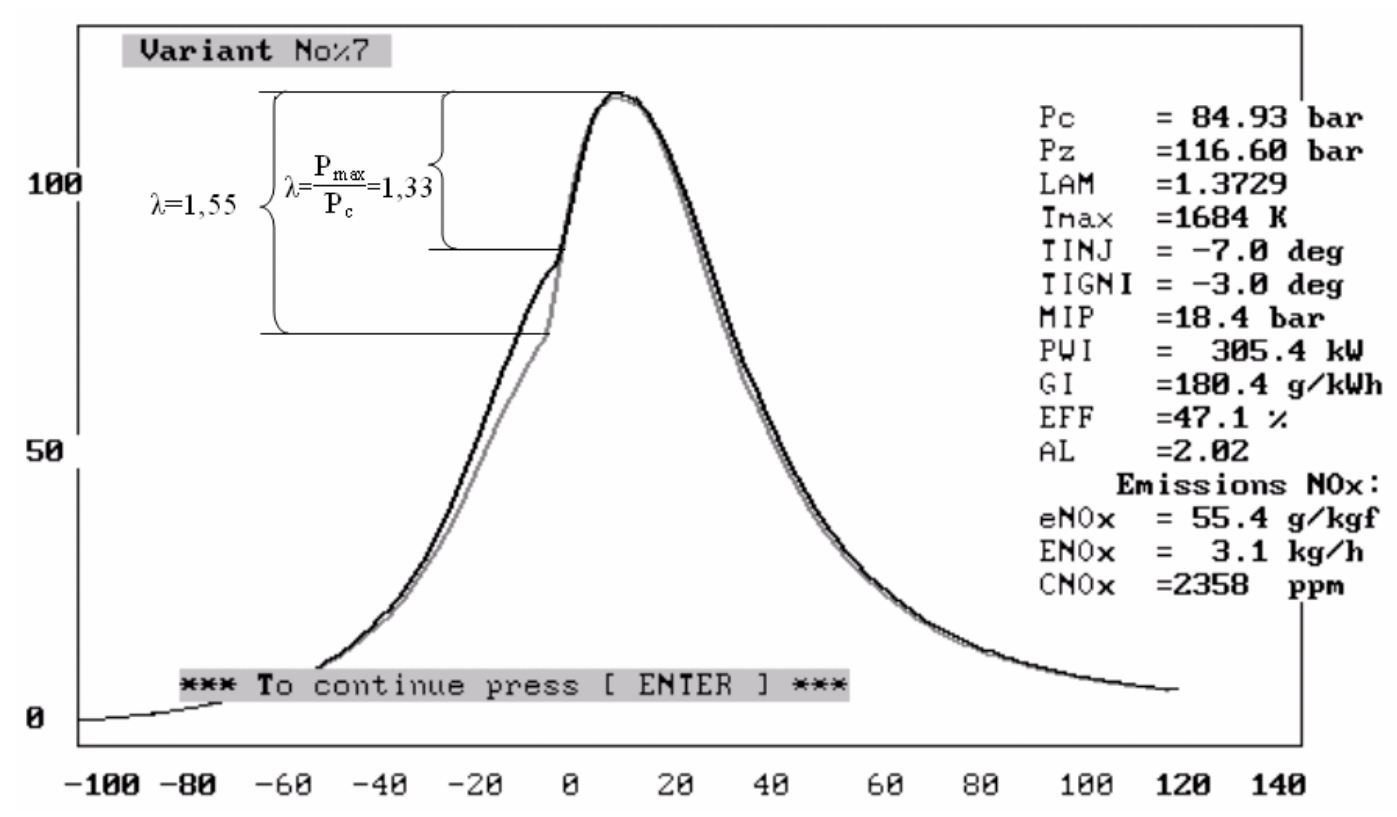

Fig 3. The collation of diagrams of indicated process with regular regulation and with optimised meanings of å and $\varphi_{\mathrm{ki}}$ 
Table 3. Efficiency of the reduction of emission of nitric oxides by the application of motor methods on the data of company MaK

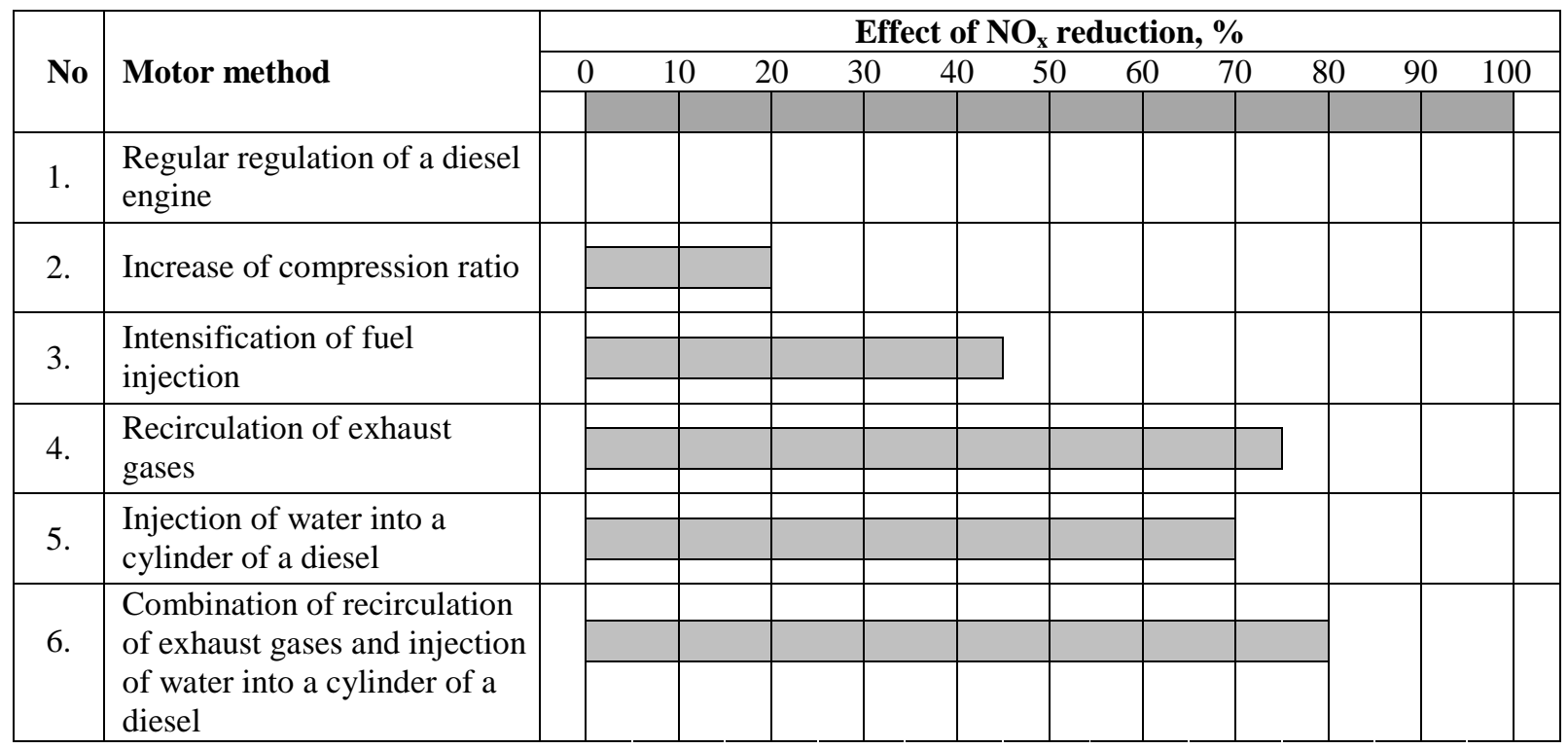

\subsection{Optimisation of air charge pressure and the phase of fuel injection}

The increase of the degree of air charging $\left(\mathrm{P}_{\mathrm{K}}\right)$ is an effective means of improvement of parameters of fuel economy of a diesel engine and its boost on average effective pressure. At the increase of $\mathrm{P}_{\mathrm{K}}$ constructive and regulating means directed on ensuring of allowable level of $\mathrm{P}_{\max }$ are simultaneously used. Until recently basic of them were: the reduction of compression ratio to a level ensuring a reliable start of a diesel engine (with a traditional system of onestep pressurization) and below (at uses of auxiliary systems of start, for example Hyperbaric or others).

However, the reduction of temperature of a working body in the cylinder at a stroke of compression (at the presence of intermediate cooling of supercharging air) is negatively reflected on the increase of the period of induction, the increase of phase of kinetic combustion and as result - the emission of $\mathrm{NO}_{\mathrm{x}}$

Successes in the improvement of parameters of systems of injection of fuel in 90 years has allowed not only to keep, but also to increase a little the level of $\varepsilon$ at pressurization of diesel engines [11, 12]. Through the increase of pressure of injection and reductions of its duration the opportunity has appeared to stabilize $\mathrm{P}_{\max }$ owing to the reduction of phase of a fuel injection without losses of fuel economy of diesel engine and at the reduction of $\mathrm{e}^{\text {NOx}}$.

In the volume of the performed research the efficiency of complex optimisation of $\varepsilon$ and $\varphi_{\mathrm{ki}}$ is appreciated.

Formal realization of the method is related with these operations which are following one by one:

1. Modelling of the increase (series in $3 \div 4$ regimes of diesel work) of supercharging pressure $\mathrm{P}_{\mathrm{K}}$ in the range which can be really performed in practice, when the meanings $b_{\mathrm{e}}, \mathrm{P}_{\text {max }}, \mathrm{e}_{\mathrm{NOx}}$ are determined under condition of $\varphi_{\mathrm{ki}}=$ const.

2. Step-by-step reduction $\left(3 \div 4\right.$ times) of $\varphi_{\mathrm{ki}}$ meanings from regular meanings and for each of them repeated calculations of the first item.

3. Determination of regimes $\left(\mathrm{P}_{\mathrm{K}}\right.$ meanings $)$ with basic level of $\mathrm{P}_{\max }$ and adequate $\mathrm{b}_{\mathrm{e}}$ and $\mathrm{e}_{\text {NOx }}$ meanings from array of the achieved results on the basis of graphic rearrangements for each series of work regime on the second item.

The example of such calculation and processing for diesel engine 6VDS 48/42 AL-2 is presented in Fig 4. The increase of charging air pressure was investigated in the diapason from 0,26 MPa up to 0,315 $\mathrm{MPa}(\sim 21 \%)$. It is achievable in practice at the change of the standard turbine of turbocharger for new with a smaller effective cross-section of orifice of the apparatus on $\sim 15 \%$.

The effect of the second method of reduction of $\mathrm{e}^{\text {' }}$ NOx is signally less in collation with the first described method. The Increase of inflation pressure from 0,26 MPa up to $0,28 \mathrm{MPa}$ with the reduction of an angle of advance of fuel injection $\varphi_{\text {ki }}$ from $11^{\circ}$ of crankshaft rotation to $7^{\circ}$ of crankshaft rotation at same time, gives the reduction of $\mathrm{e}^{\prime}{ }_{\mathrm{NOx}}$ not more than $4 \div 5 \%$ and for diapason $\mathrm{P}_{\mathrm{K}}>0,28 \mathrm{MPa}$ emission of $\mathrm{NO}_{\mathrm{x}}$ is stabilized on the level of $57 \div 57,5 \mathrm{~g} /(\mathrm{kg}$ fuel $)$.

The achieved results could be explained by the conditional less level of emission of $\mathrm{NO}_{\mathrm{x}}$ in diesel en- 


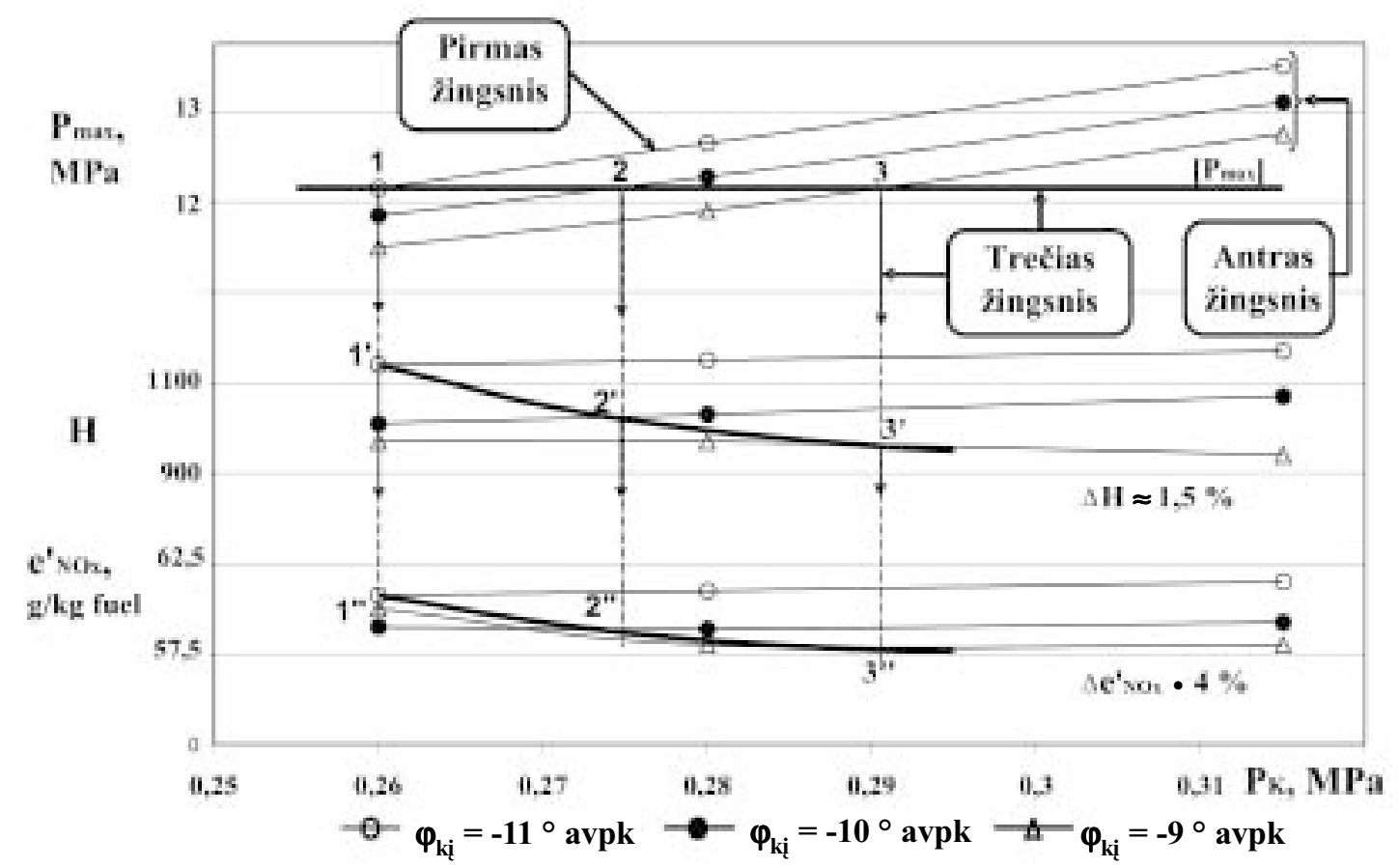

Fig 4. Optimisation of the pressure of air charging and phase of fuel injection of diesel type 6VDS 48/42 AL-2

gines of type 6VDS 48/42 AL-2. The Effectiveness of the influence of an angle of advance of fuel injection for the reduction of emission of $\mathrm{NO}_{\mathrm{x}}$ is appreciable when $\mathrm{e}_{\mathrm{NOx}} \geq 14 \div 15 \mathrm{~g} / \mathrm{kWh}$ [11].

The emission of nitric oxides $\mathrm{e}_{\mathrm{NOx}}$ is $\sim 12 \mathrm{~g} / \mathrm{kWh}$ for the investigated level of formation and in regular regulation of an object. For the mentioned reasons the reduction of dynamics of phase of kinetic combustion under the reduction of $\varphi_{\mathrm{ki}}$ practically only compensates the increase of emission of $\mathrm{NO}_{\mathrm{x}}$ caused by the increase of temperature of flame causing the increase of the amount of oxygen in the excess charge of air.

\section{Generalized dependences of the parameters of an indicated process}

The large positive experience of the application of generalized integral indexes of cycle $\left(\alpha, \varepsilon, \lambda, T_{K}\right.$, $\mathrm{P}_{\mathrm{K}}$ etc.) is obtained at the optimisation of parameters of the indicated process for the fuel economy. Their registration by dimensionless complexes $\left(\mathrm{P}_{\max } / \mathrm{P}_{\mathrm{K}}\right.$; $\mathrm{P}_{\max } / \mathrm{P}_{\mathrm{mi}} \times \mathrm{T}_{\mathrm{K}} / 350$ etc.) enables to present visually the directions of optimisation on the mentioned parameters $[7,8]$.

Also there are enough successful theoretical decisions and analogous methods of the realization in practice in the area of thermal stress [14]. The Method uses the limited amount of arguments which registration is fully performed directly in the object - diesel engine of the ship. For this reason the further im- provement of the mentioned method from the point of evaluation of emission of $\mathrm{NO}_{\mathrm{x}}$ was accepted as purposeful in this research also. On the basis of experimental and theoretical work of many scientists [12, $13,15]$ the relation between the emission of nitric oxides $\mathrm{e}_{\text {NOx }}$ and relative quantity of heat $\mathrm{X}_{\mathrm{I}}$ released in a stage of kinetic combustion is determined and analyzed.

The determination of a relative quantity of heat $\mathrm{X}_{\mathrm{I}}$ is separate investigation based on the modelling of indicated diagram. The large amount of data is necessary for the correct realization of this investigation. At the determination of a physically reasoned relation between a relative quantity of heat $X_{I}$ and integral parameters of a cycle there is a comfortable mathematical apparatus for the determination of the dependence of emission of NOx on the integral parameters $\mathrm{e}_{\mathrm{NOx}}=\mathrm{f}\left(\alpha, \varepsilon, \lambda, \mathrm{T}_{\mathrm{K}}, \mathrm{P}_{\mathrm{K}} \ldots\right)$.

\section{Relation between a relative quantity of heat $X_{I}$ and the parameters of an indicated process}

The relative quantity of heat $X_{I}$ released in a cycle up to the moment when the maximal pressure of a cycle $P_{\max }\left(\varphi_{P \max }\right)$ is achieved without including of losses in walls of the cylinder and work of gases from its rather small meaning from the beginning of combustion $\varphi_{\mathrm{c}}$ up to $\varphi_{\mathrm{Pmax}}$ is determined by the equation of the first law of thermodynamics:

$\Delta Q_{P \max }=Q_{P \max }-Q_{c}=c_{v}^{\prime \prime} T_{P \max } \times G_{d}-c_{v}^{\prime} T_{c} G_{\text {air }},(4)$ 
where:

$Q_{P \max }, Q_{c}$ - quantity of heat given for a working body in the cylinder according to the moments $\varphi_{P \max }$ and $\varphi_{c}, \mathrm{~kJ} ; c_{v}^{\prime}, c_{v}^{\prime \prime}$ - specific heat of charge of exhaust gases and air, $\mathrm{kJ} / \mathrm{kg}$ fuel; $T_{P_{\max }}, T_{c}$ - temperature of charge of gases and air , K; $G_{d}, G_{a i r}$ - mass of charge of gases and air at typical moments, $\mathrm{kg}$.

According to the allowable assumption of an initial phase of kinetic combustion, when $c_{v}^{\prime} \approx c_{v}^{\prime \prime}$ and $G_{d} \approx G_{\text {air }}$ (4) equation is altered as follows:

$\Delta Q_{P \max }=c_{v} G_{\text {air }} T_{c}\left(V_{c} / V_{P \max }\right)\left[\lambda-\left(V_{c} / V_{P \max }\right)\right]$, (5)

where:

$V_{P_{\max }}, V_{c}$ - working capacity of a cylinder at the moments $\ddot{O}_{\mathrm{Pmax}}$ and $\varphi_{\mathrm{c}}$.

After the insertion in the equation (5) of meanings $V_{c}$ and $V_{P \max }$, expressed through capacity of the cylinder and adequate compression ratio, we receive the equation:

$$
\begin{aligned}
& \Delta Q_{P \max }=c_{v} G_{a i r} T_{c}\left(\varepsilon_{c}-1\right) /\left(\varepsilon_{P \max }-1\right) \times \\
& {\left[\lambda-\left(\varepsilon_{c}-1\right) /\left(\varepsilon_{P \max }-1\right)\right],}
\end{aligned}
$$

where:

$\varepsilon_{P \max }, \varepsilon_{c}-$ compression ratio at the moments $\varphi_{P \max }$ and $\varphi_{c}$.

Meanings $\varepsilon_{c} \approx \varepsilon_{P \max }$, and equation are transformed as follows:

$$
\Delta Q_{P \max }=c_{v} G_{\text {air }} T_{c}(\lambda-1) .
$$

By using dependence Gair $=\mathrm{G}_{\mathrm{f}} \stackrel{\mathrm{i}}{\mathrm{L}} \mathrm{L}_{\mathrm{o}}$ $\left(\mathrm{L}_{\mathrm{o}}-\right.$ stoichiometric constant) we achieve:

$$
\Delta Q_{P \max }=c_{v} G_{f} \alpha L_{0} T_{K} \varepsilon^{n_{1}-1}(\lambda-1),
$$

where:

$G_{f}$ - cyclic portion of fuel, $\mathrm{kg} ; T_{K}$ - temperature of beginning of compression, $\mathrm{K} ; \alpha$-real coefficient of excess of air; $n_{l}$-index of polytrope of compression.

Relative quantity of heat $\mathrm{X}_{\mathrm{I}}\left(\mathrm{X}_{\mathrm{Pmax}}\right)$ released in the cylinder up to the moment of $\varphi_{P \text { max }}$, is determined by the dependence:

$X_{I}\left(X_{P \max }\right)=\Delta Q_{P \max } / G_{f}=c_{\nu} \alpha L_{0} T_{K} \varepsilon^{n_{1}-1}(\lambda-1)$.

Multivariational results of the performed calculations showed that the influence of made assumptions could be evaluated by the constant multiplier $\mathrm{K}$ without substantial influence on the final result at alteration of equation and $\mathrm{X}_{\mathrm{I}}\left(\mathrm{X}_{\mathrm{P} \max }\right)=\mathrm{K} \times \mathrm{H}$, where $\mathrm{H}=\alpha \mathrm{T}_{\mathrm{K}} \varepsilon^{\mathrm{n} 1-1}(\lambda-1)$ - complex index of working parameters. The results of analytical interrelations $\mathrm{X}_{\mathrm{I}}=\mathrm{f}\left(\alpha, \varepsilon, \lambda, \mathrm{T}_{\mathrm{K}}, \mathrm{P}_{\mathrm{K}}\right)$ are applied for series of high speed diesel engines of company "Motoren Und Turbinen Union" - V396TC4 [15] and for the object of this investigation, medium speed diesel engine 6VDS 48/42 AL-2 (Fig 5). For diesel engine 8V396TC4 the data of experimental research were used, where the measurements of emission of NOx were performed. For diesel engine 6VDS 48/42 AL-2 the results of mathematical modelling of their parameters were used.

The relation close to linear between $\mathrm{X}_{\mathrm{I}}$ and complex index $\mathrm{H}=\alpha \mathrm{T}_{\mathrm{K}} \varepsilon^{\mathrm{n} 1-1}(\lambda-1)$ and its coefficient of correlation $\mathrm{R}^{2}=0,9026$ was determined. In a wide range of change of $\mathrm{P}_{\mathrm{me}}, \mathrm{n}$, constructive and regulating parameters $\left(\mathrm{P}_{\mathrm{K}}, \varphi_{\mathrm{ki}}, \varepsilon\right)$ dependences $\mathrm{e}_{\mathrm{NOx}}=\mathrm{f}(\mathrm{H})$ are determined and their coefficients of correlation are: for diesel $8 \mathrm{~V} 396 \mathrm{TC} 4-\mathrm{R}^{2}=0,8982$, for diesel $6 \mathrm{VDS} 48 / 42 \mathrm{AL}-2-\mathrm{R}^{2}=0,8715$. A wide range of the

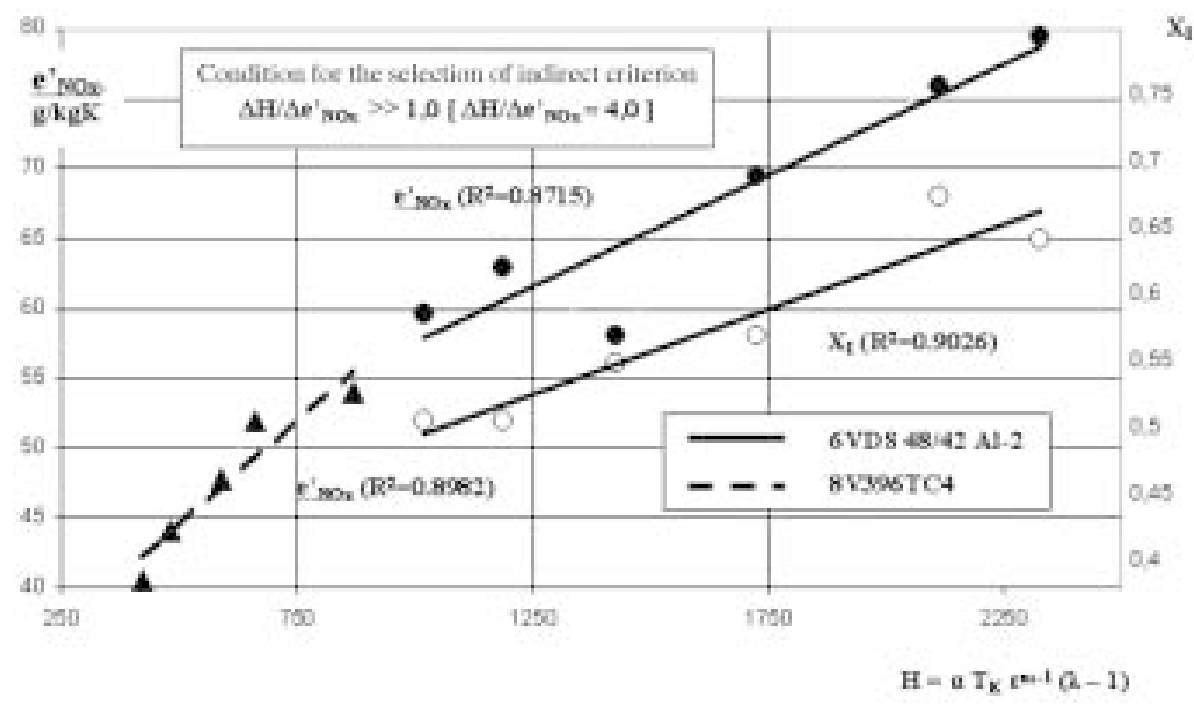

Fig 5. Fragments of approbation of the results of analytical interrelations $X_{I}=f\left(\alpha, \varepsilon, \lambda, T_{K}, P_{K}\right)$ of diesel engines V396TC4 and

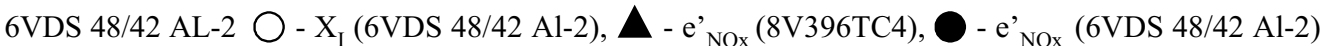


change of criterion $\mathrm{H}$ is: for diesel $8 \mathrm{~V} 396 \mathrm{TC} 4$ - from 420 up to 870, for diesel 6VDS 48/42 AL-2 - from 1020 up to 2330 . The change of $X_{\text {I }}$ didn't exceed $16 \%$ and it was $\sim 4$ times less than the change of $\mathrm{H}$. As a result the achieved proportion of the changes $\Delta \mathrm{H} / \Delta \mathrm{X}_{\mathrm{I}} \approx 4,0$ what meets one of the main requirements $\Delta \mathrm{x} / \Delta \mathrm{y}>>1,0$ choosing the indirect criterion for $\mathrm{x}$ function from $\mathrm{y}$.

The achieved result gives the opportunity to evaluate the influence of the main constructive and regulating parameters of a diesel engine on the emission of nitric oxides and solving of tasks of the improvement of diesel indexes. As an example, the addition of universal characteristic of diesel with isometric dependence $\mathrm{H}=\mathrm{f}\left(\mathrm{P}_{\mathrm{me}}, \mathrm{n}\right)$ allows to harmonize the characteristics of power aggregate and propeller not only with the evaluation of specific fuel consumption $b_{e}$, but with the emission of nitric oxides $e_{\text {NOx }}$ also.

The data of this research have shown that for the reduction of specific fuel consumption and the emission of nitric oxides for diesel 6VDS 48/42 AL-2 the transfer of work of a diesel engine in the zone of low revolutions is expedient: the reduction of rotations by $10 \%$ ensures the reduction of emission of $\mathrm{NOx} \sim$ by $5 \%$.

\section{Conclusions}

1. There is performed approbation of the interapplication of computer programs with a different level of elaboration for the optimisation of the main indexes of medium speed diesel engines (fuel economy, reliability, emission of harmful components in exhaust gases).

2. The investigated efficiency of separate motor methods is applied for the types of diesel engines 6VDS 48/42 AL-2 which are widely spread in the fleet of Lithuania. It is determined that the optimization of compression ratio, phase of fuel feeding and parameters of a system of pressurization of air allows to reduce by $5 \div 10 \%$ of emission of nitric oxides at the preservation of parameters of fuel economy and reliability at the same level.

3. For the performance of further investigations the indirect criterion $\mathrm{H}=\alpha \mathrm{T}_{\mathrm{K}} \varepsilon^{\mathrm{n1}-1}(\lambda-1)$, which estimates the phase of kinetic combustion and emission of nitric oxides and displays the interrelation of the indicated parameters of a diesel is offered. Its successful adaptation for a wide range of regimes of speed and load for diesel types 8V396TC4 and 6VDS 48/42 AL-2 is performed. Coefficients of correlation of functional dependences $\mathrm{X}_{\mathrm{I}} \mathrm{e}^{{ }^{\prime}{ }_{\text {NOx }}}=\mathrm{f}(\mathrm{H})$ are $\mathrm{R}^{2}=0,87 \div$ 0,90 and this gives the opportunity of their reasonable application for further research.

\section{References}

1. Smailys, V. The perspective of development of sea transport of Lithuania and ecological problems. Transport Engineering (Transportas), t. XIV, No 2, Vilnius: Technika, 1999, p. 354-411.

2. Lebedevas, S. Saving of energy resources in railway transport by improvement of characteristics of fuel consumption of railway diesel engines Transport Engineering (Transportas), Vol XVII, No 1, Vilnius: Technika, 2002, p. 30-37.

3. Marine power systems. The ship power supplier. Wartsila, 2001, p. 59.

4. Man $B \& W$ diesel engines service and maintanance manual. Man B\&W company, 2000, p. 358.

5. Regulation for the prevention of air pollution from ships. Annex VI to International Conventional MARPOL 73/78, IMO, 1996. London.

6. Kavtradze, R. Z. Local exchange of heat in piston type diesel engines (Локальный теплообмен в поршневых двигателях). Moscow: MGU name of N. E. Bauman, 2001. 592 p. (in Russian).

7. Pogodin, S. I. Work processes of turbo-piston type transport engines (Рабочие процессы транспортных турбопоршневых двигателей) Moscow: Mashinostrojenyje, 1978. 311 p. (in Russian).

8. Ivanchenko, N. N.; Krasovskij, O. G.; Sokolov, S. S. High turbocharging of diesels (Высокий наддув дизелей). St. Petersbourg: Mashinostrojenyje, 1983. 198 p. (in Russian).

9. Punda, A. S. Calculating modelling of work process of ship diesel engines (Численное моделирование рабочих процессов судовых дизелей). Moscow: Mortechinformreklama, 1995. 64 p. (in Russian).

10. Vagner, V. A.; Novoselov, A. L.; Rusakov, V. Modelling of formation of toxic materials in the cylinder of diesel engine (Моделирование образования вредных веществ в цилиндре дизеля). In: Development of machines, diesels and heat energy units. Set of scientifical works MGTU-AltGTU. Barnaul, 2000, p. 51-59 (in Russian).

11. Vogt, R. The MaK emission concept exemplified by the M32. MAK Toplaterne, 1994, No 68, p. 12-15.

12. Needham, J. R.; Doyle, D. M.; Nikol, A. J. The Low $\mathrm{NO}_{\mathrm{x}}$ Truck Engine Needham In: SAE Techn. Pap. Ser. 1991, No 310731, p. 1-10.

13. Smailys, V.; Bykov, V. J. Optimisation of parameters of economy and ecology for diesels $\mathrm{ChN} 21 / 21$ by boosting on medium effective pressure. Engine-building (Двигателестроение), 1990, No 4, p. 44-46 (in Russian).

14. Lebedev, S. V. Engineering methodology for complex calculating optimization of parameters of high speed diesel engines. Engine-building (Двигателестроение). 1998, No 3, p. 5-12 (in Russian).

15. Kruggel, O. Progress in the combustion technology of high performance diesel engines toward reduction of exhaust emissions without reduction of operation economy. Baden-Wurttemberg Thechnology Conference, Oslo, 1989. 14 p. 